\title{
The assassination of experience by photography
}

Daniel Rubinstein

One way of thinking about the ways in which photography contributed to the experience of fine art, and perhaps to the structure of experience itself, is as the primary driver and a catalyst of modernist aesthetics. According to this view, photography is entangled in the visual strategies of modernism and the avant-guarde both as part of the mode of reproduction inherent in the development of industrial capitalism and as the key modality by which the contemporary myth of the artist came to be expressed. In other words, photography can be seen as the medium by which the art establishment came to assert its elite status while at the same time providing it with an aesthetic lens that fetishized the snapshot as the ultimate expression of the Duchampian notion of the 'readymade'.

By giving every member of society a recognisable and recordable face that could be preserved in a family album, stored in a police file and exhibited in a museum, photography acted as the catalyst for the creation of the modern individual as someone who spends their life as a passive spectator of flickering images while at the same time being exposed to universal procedures of recording and surveillance. The determining factor here is that both as a form of mass entertainment and of social control, photography is marked by a rational and logical relationship among images and the world they allegedly represent. In what follows, I will suggest that when the engagement with photography is limited to questions of recognition and resemblance, such approach stifles our experience of the world and directs us towards monotonous homogeneity in which everything can be represented in a photograph, and a 
photograph is always a representation of something or other. And yet, a photograph has the potential to move our gaze beyond representation of events and situations in a way that allows us to penetrate the appearance of things and to sense their inner truth, rather than act as a mere illustration.

As two brief examples, we might think of the photograph in a passport that is used to verify the identity of its owner when the border control (human or facial recognition algorithm) compares the resemblance between the image and the person, and then, in a different (but connected) manner, the video recording made by Diamond Reynolds of the aftermath of her boyfriend, Philando Castile being shot by police officers, which was viewed by millions of people online, and acted as a catalyst to the 'Black lives matter' movement. In the first case, the passport photo speaks not only about the similarity between the image and the person, but also about a system of power and control that attributes a legal status to visual resemblance, and legitimises the passing of judgement that is based on visual appearance alone. In the second example, the cameraphone recording transcends the logic of recognition, in which we see a black man bleeding out next to his girlfriend after being shot by police, and conclude that this must be a terrible situation to find oneself in. What is presented to the viewer through the images and the voices that the camera captured, is not only a documentation of an event, but also the perception of a reality that is bigger and more complex that any representation. Rather than being a faithful documentation of something that happened, this footage acquires a certain autonomy from the event it recorded, releasing from it a force that is haunting and scarring the viewer. While we can never feel what it was like to be in that car during that shooting, the jittery recording of the car window that frames the policeman on an ubiquitous sidewalk shouting hysterically, combined with the calm, repetitious narration by Diamond 
Reynolds who is talking both to the officer and to us, simultaneously responding to orders to show her hands and reporting her boyfriend's death and her own arrest, suggest that violence, racism and fear are both everyday occurrences in suburban America and that they have a specific visual form that this video recording managed to capture.

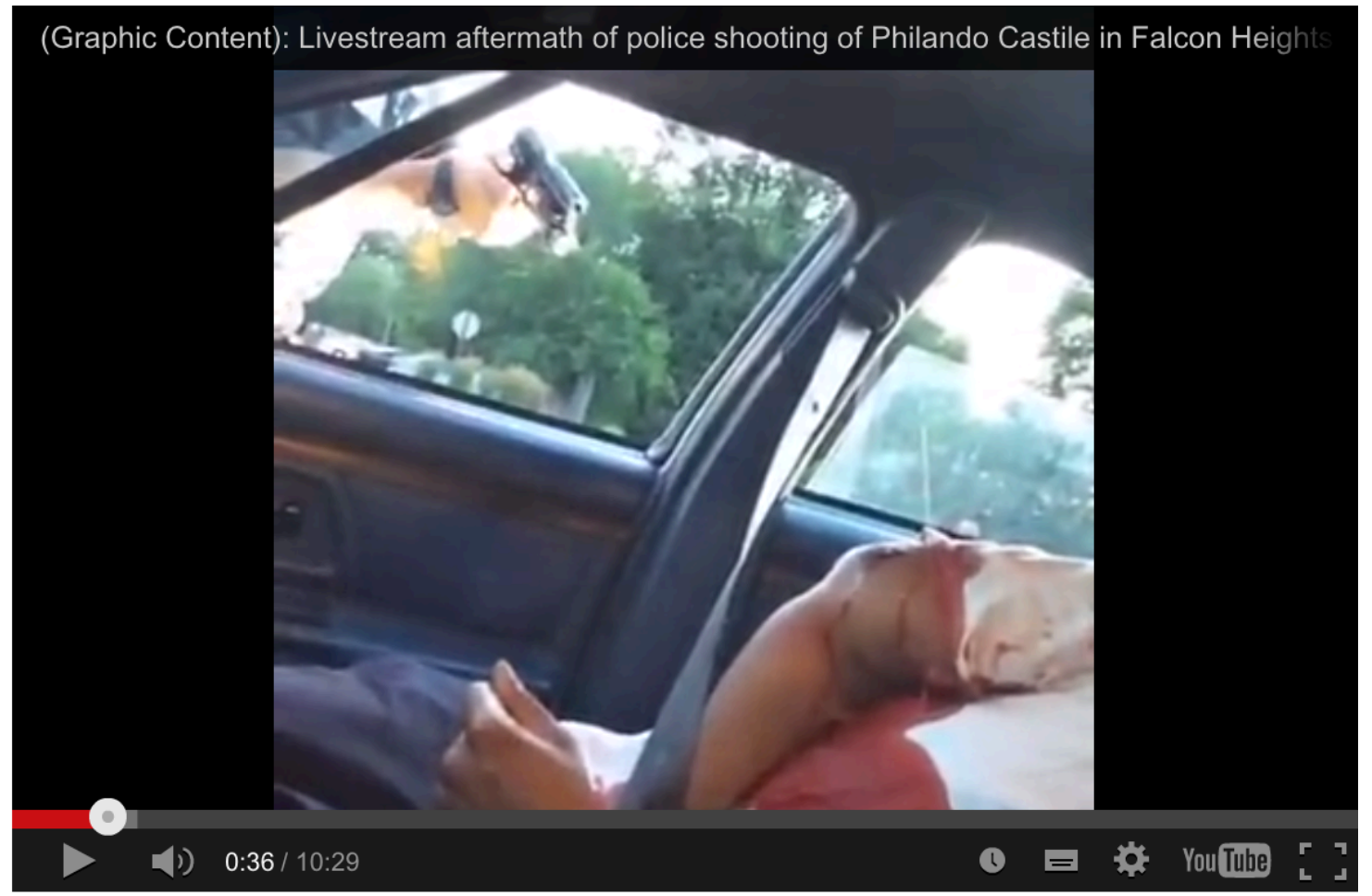

In both cases discussed above the image acts not only as a rational representation of an external reality, and its authority and agency are anchored not only in our naive belief in photography's ability to simply record a world of people, objects and events just as it is. Rather, what we are able to glimpse is the autonomy of the photographic image (both moving and still), and its ability to expose the power of the image qua image to shape and intervene in the world around us. What we are witnessing is not a representation of pre-existing reality, but the photograph allows us to intuit that the visual image is endowed with unique power, and that the power of photography lies not in its ability to represent, but in asserting the materiality of visual perception. 
How might we begin to think about the materiality of photography in a way that frees it from a dependence on representation? Consider for instance the slideshow REM (2016) by Kenta Cobayashi (with God Scorpion and Molphobia): the sequence is dominated by a continuous movement through an imaginary landscape constructed from parts of photographs, liquefied billboards and morphed walls, surrounded by reflective, water-like surface. Floating through this world one might think of gliding the canals of Venice, or of Ridley Scott's panning shoots of the post-apocalyptic New York in Blade Runner (1982). And yet, in REM every solid composite that first appears to the eye as a billboard or a wall of a building is revealed to be nothing more (or less) than a surface: the camera pierces each surface in turn, revealing another surface behind it, that - like the previous one - appears solid at first, but has no other substance than the data it is made of. What this work allows us to experience is that beyond the compositional elements of an image lies its material condition of continuous repetition, copy and self-replication. Jean-Francois Lyotard named this condition 'The Great Ephemeral Skin'. In Libidinal Economy he proposed that the role of the artist is to lay bare the mechanisms of representation, to show that if there is anything real about representation, it is because there also exists a fully real virtual domain constructed not from objects and things, but from intensities, desires and surfaces:

The representative chamber is an energetic dispositif. To describe it and to follow its functioning, that's what needs to be done. No need to do a critique of metaphysics (or of political economy, which is the same thing), since critique presupposes and ceaselessly creates this very theatricality; rather be inside and forget it, that's the position of the death drive, describe these foldings and gluings, these energetic vections that establish the theatrical cube with its six homogenous faces on the unique and heterogeneous surface. (Lyotard 2004, p. 3) 


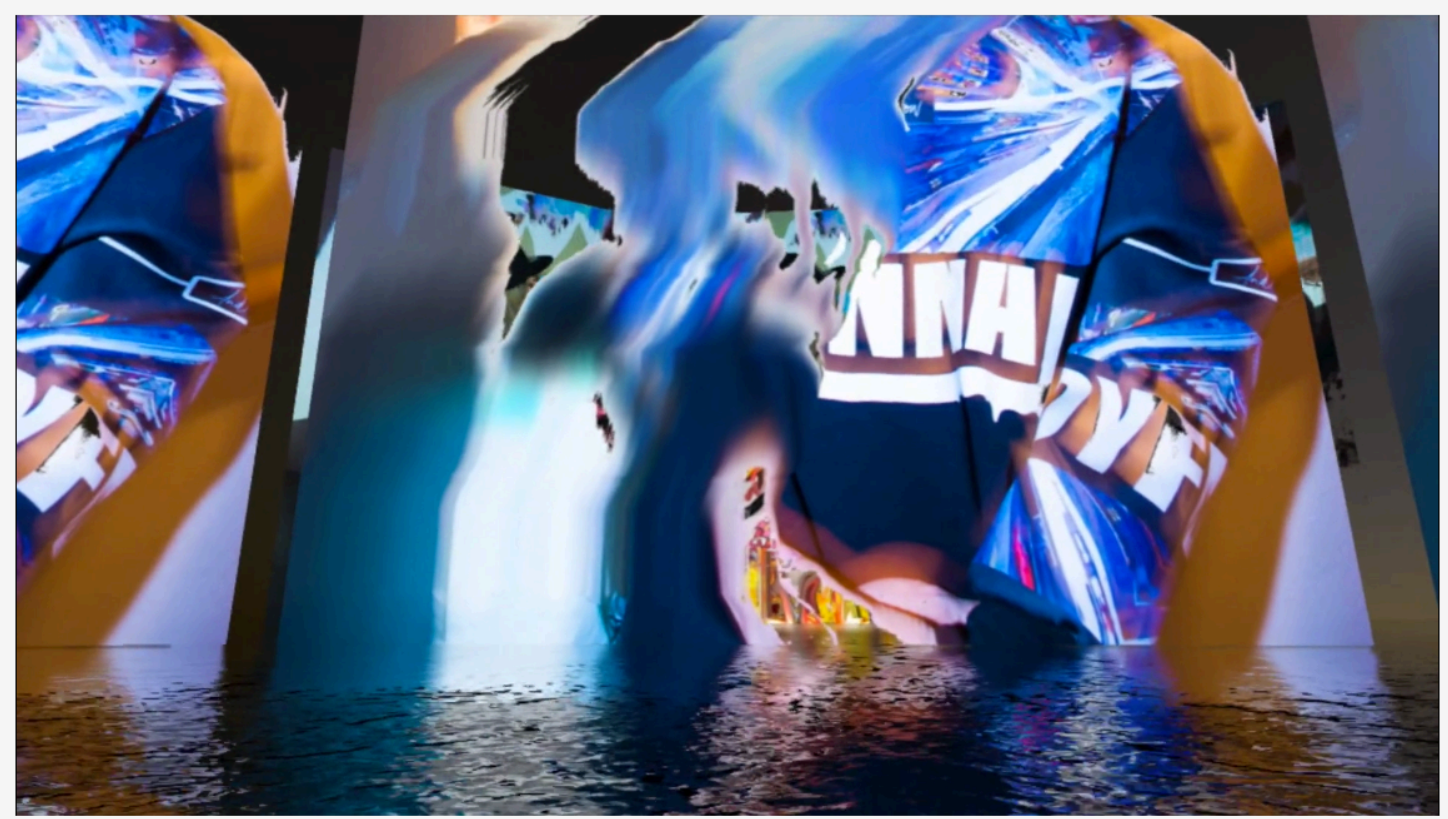

Slideshow 'REM' 4min49sec. 2016 Collaboration with a media artist God Scorpion and a track maker Molphobia.

In REM photography is being revealed not as a 'representative chamber', but as an infinite movement of surfaces that continuously self-replicate and morph into each other. The laws of matter in a three dimensional world do not apply to the great ephemeral screen on which images proliferate, as on this screen the logic of Euclidian geometry is replaced by the evolving symmetry of fractal geometry. This is not because photography here is rejecting a reference to reality, but because reality itself is understood as photographic and for that reason indefinitely signified, continuously recurring, subject to the logic of technology, mass-production and the perpetual reformulation of commodities for new markets.

In its traditional form photography expresses the potential for representation located within capitalist organization of society. But when photography is detached from its ability to produce representations and considered as a flow of image-data, one arrives at another fully real force that springs from photography's ability to produce rhythms and not forms, reproduce and not represent, proliferate and not identify, selfreplicate and not copy. As a process of instantaneous distribution, photography is being 
detached from objects in space as it poses a question about the condition of seeing as such. Instead of evaluating images on the basis of their similarity to actual events or situations, instead of re-examining their indexical or symbolic content, what is required is to inquire after the conditions that make something like an image possible. By exploring the rules of engagement that govern the use of images, it might be possible to free thought from its dependence on the Platonic opposites of image (eikon) and Reality (eidos) (The Republic, $601 \mathrm{~b}-\mathrm{c}$ ), and from the binary dualisms that follow from it. For as long as the rule of this binary model persists, it is impossible to escape what Deleuze branded as 'the four iron collars of representation: Identity in the concept, opposition in the predicate, analogy in judgment and resemblance in perception.'

(Deleuze 2004, p. 330)

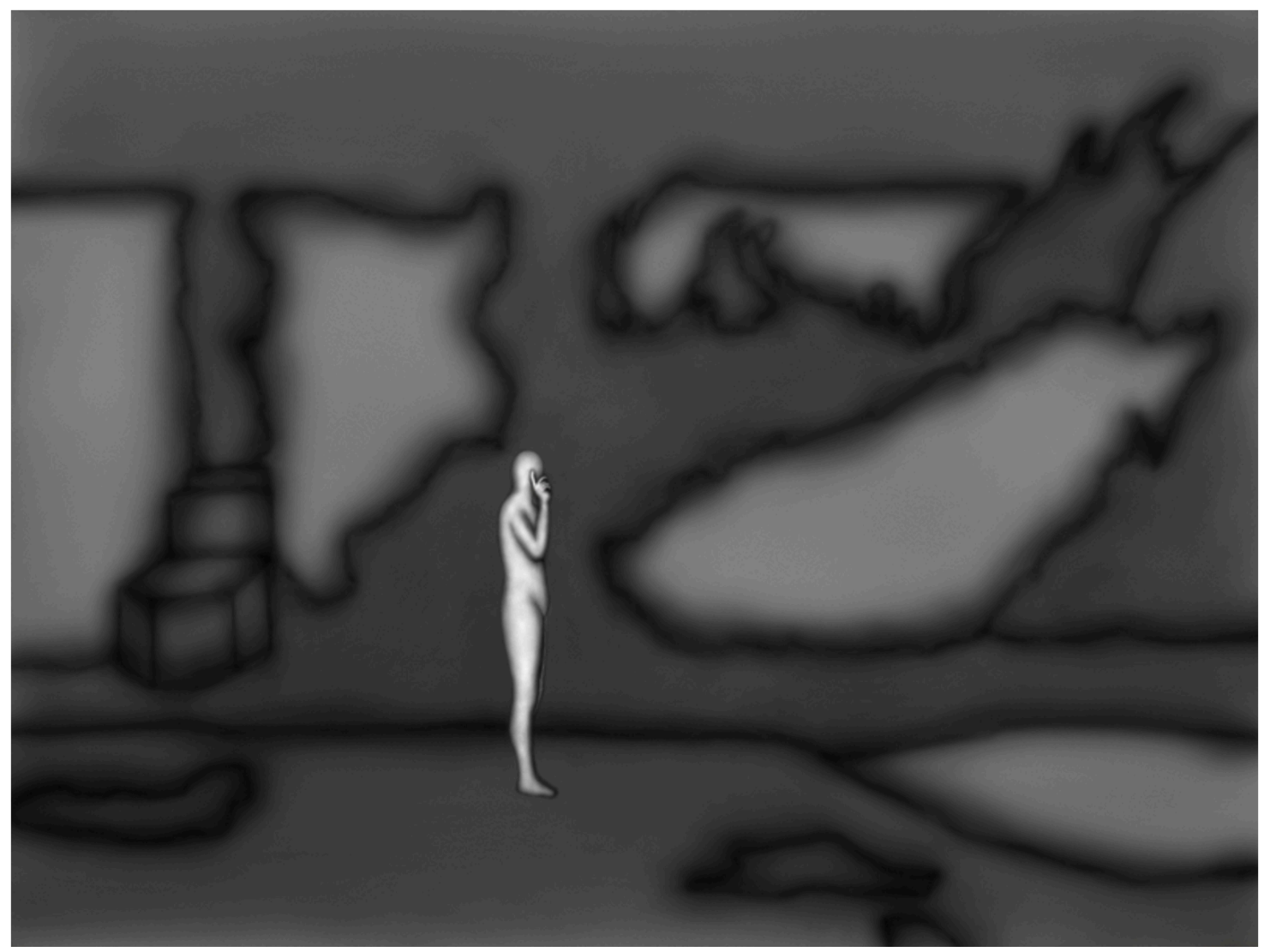

Daisuke Yokota, Interception 2009 
The work of Daisuke Yokota can be considered in this light, as an attempt to draw attention away from representation, to the process that can make a picture possible. By working with aspects of image production, Yokota approaches the visual via a series of transformations that tend to obscure, obliterate and deface the optical surface while simultaneously creating an image that exposes the strategies of image making. Yokota's works could be read as a critique of traditional photography's antiphotographic tendencies: by privileging sharpness, clarity and realism photography modelled itself on how the human subject wants to see the world, rather then insisting on a view of the world that is inherently photographic. The camera lens is not the same as a human eye, and the chemical or algorithmic processing is not the same as the processing of visual stimuli by human brain. Because the camera is not a human prosthetic limb, it can create images that are divorced from the way the world presents itself to a human subjectivity. Crucially, photography can show us the world not as it appears to a spectator, but as a collection of perceptions of intensity, before they are submitted to the logic of representation. To say the same thing slightly differently, it is not me who is making images of the world, rather by encountering the world as an image, I become who I am. In the famous opening paragraphs of Matter and Memory, Henri Bergson explains:

Here I am in the presence of images, in the vaguest sense of the word, images perceived when my senses are opened to them, unperceived when they are closed. All these images act and react upon one another in all their elementary parts according to constant laws which I call laws of nature, and, as a perfect knowledge of these laws would probably allow us to calculate and to foresee what will happen in each of these images, the future of the images must be contained in their present and will add to them nothing new. Yet there is one of them which is distinct from all the others, in that I do not know it only from without by perceptions, but from within by affections: it is my body. (Bergson 2005, p. 17) 
Externally I might see a tree, a dog or a house, but internally all I can sense is images and I experience my own body as an image. Photography then is not an accidental invention or a random discovery of the technological age, but rather it is rooted in the very process that is making human beings out of animals and political subjects out of humans. The photograph is giving us an image of the world that is not human because it is not constrained to the subjective processes of representation. Instead, the photograph interrupts the relationship between us and the world, producing familiarity and repetition on the one hand and openness towards new, previously unknown forms of experience on the other.

All this means that photography is not a tool that is making us look further, remember better and record everything for posterity, rather, it is a way of experiencing reality as layered amalgam of data connected through processes of repetition, selfreplication and copy. The power of photography, its enduring fascination and mystery is that is allows us to see the world not reduced to the view of the human eye.

\section{References}

Bergson, H., 2005, Matter and memory, Translated by Paul \& Palmer. Zone books, N.Y.

Deleuze, G., 2004, Difference and repetition, Translated by P. Patton. Continuum, London.

Lyotard, J.F., 2004, Libidinal economy, Translated by Hamilton Grant. Continuum, London.

Plato 1997, The Republic, in DS Hutchinson \& JM Cooper (eds), Complete works, Hackett Pub, Indianapolis, Ind. 